\title{
IR and electrochemical synthesis and characterization of thin films of PEDOT grown on platinum single crystal electrodes in [EMMIM] $\mathrm{Tf}_{\mathbf{2}} \mathbf{N}$ ionic liquid
}

\author{
Andrea P. Sandoval ${ }^{1,2}$, Marco F. Suárez-Herrera ${ }^{1}$ and Juan M. Feliu ${ }^{* 2}$
}

\section{Full Research Paper}

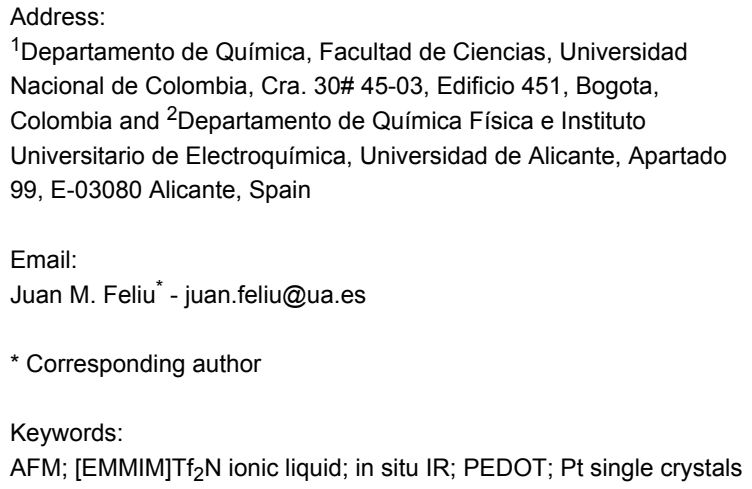

${ }^{1}$ Departamento de Química, Facultad de Ciencias, Universidad Nacional de Colombia, Cra. 30\# 45-03, Edificio 451, Bogota, Colombia and ${ }^{2}$ Departamento de Química Física e Instituto Universitario de Electroquímica, Universidad de Alicante, Apartado 99, E-03080 Alicante, Spain

Email:

Juan M. Feliu* - juan.feliu@ua.es

* Corresponding author

Keywords:

AFM; [EMMIM]Tf $f_{2} \mathrm{~N}$ ionic liquid; in situ IR; PEDOT; Pt single crystals

\author{
Beilstein J. Org. Chem. 2015, 11, 348-357. \\ doi:10.3762/bjoc. 11.40 \\ Received: 28 November 2014 \\ Accepted: 18 February 2015 \\ Published: 13 March 2015 \\ This article is part of the Thematic Series "Electrosynthesis". \\ Guest Editor: S. R. Waldvogel \\ (C) 2015 Sandoval et al; licensee Beilstein-Institut. \\ License and terms: see end of document.
}

\begin{abstract}
Thin films of PEDOT synthesized on platinum single electrodes in contact with the ionic liquid 1-ethyl-2,3-dimethylimidazolium triflimide $\left([\mathrm{EMMIM}] \mathrm{Tf}_{2} \mathrm{~N}\right)$ were studied by cyclic voltammetry, chronoamperometry, infrared spectroscopy and atomic force microscopy. It was found that the polymer grows faster on $\operatorname{Pt}(111)$ than on $\operatorname{Pt}(110)$ or $\operatorname{Pt}(100)$ and that the redox reactions associated with the PEDOT p-doping process are much more reversible in [EMMIM] $\mathrm{Tf}_{2} \mathrm{~N}$ than in acetonitrile. Finally, the ion exchange and charge carriers' formation during the p-doping reaction of PEDOT were studied using in situ FTIR spectroscopy.
\end{abstract}

\section{Introduction}

Conducting polymers have been subject of an intense research during the last decades because they exhibit high conductivity and interesting optical properties. These properties allow their use in several electronic devices [1,2]. The poly(3,4-ethylenedioxythiophene) (PEDOT) is one of the most conducting and stable (thermal and chemical) conducting polymer. For these reasons PEDOT thin films have been extensively studied [3].

Special attention has been paid to the use of electrochemical methods to synthesize conducting polymers due to the high degree of control afforded during the polymerization reaction. On the other hand, thin films of conducting polymers are more suitable to explore electrochemical properties such as stability, capacitance, resistance, ionic exchange kinetics and electrocatalysis [4].

Besides the synthesis technique, there are two important factors that can influence the polymer properties: the surface structure of the electrode and the solvent used [2,5]. It has been reported that the nucleation and growth kinetics, and the electrochemical properties, as the ionic resistance or the electrocatalytic activity, of PEDOT are affected by the surface energy state of the electrode [6]. For example, it was found that the ionic resistance of the PEDOT films electrochemically synthesized on platinum 
electrodes increases in the order $\operatorname{Pt}(100)<\operatorname{Pt}(110)<\operatorname{Pt}(111)$ [6]. The synthesis of other conducting polymers on well-defined surfaces [7-10] and templates [11] also has shown how the surface affects their adhesion, coverage, morphology and redox kinetics.

On the other hand, the synthesis of conducting polymers in ionic liquids (ILs) has shown an enhancement in stability, organization and electroactivity [12-14]. These characteristics are obtained mainly because of the dry medium, their wide electrochemical window, and their low nucleophilicity. Therefore, during the electrosynthesis of conducting polymers the overoxidation of the polymer is less probable and the average length of the polymer chains is higher in ionic liquids than in molecular solvents [15].

In this work, Pt single crystals electrodes and the moisture stable IL 1-ethyl-2,3-dimethylimidazolium triflimide, [EMMIM] $\mathrm{Tf}_{2} \mathrm{~N}$ [16], are used to carry out the electrochemical synthesis of PEDOT. The electrochemical properties of thin films of PEDOT are subsequently studied and compared with the behavior obtained in acetonitrile.

\section{Results and Discussion Cyclic voltammetry}

Figure 1 shows the cyclic voltammograms of EDOT in [EMMIM] $\mathrm{Tf}_{2} \mathrm{~N}$. The onset of the EDOT oxidation begins at $0.9 \mathrm{~V}$ in $\operatorname{Pt}(111)$ and $\operatorname{Pt}(110)$ while in $\operatorname{Pt}(100)$ it starts at $1.0 \mathrm{~V}$. The loop observed during the first scans (Figure 1a - insert) is typical of the electrosynthesis of conducting polymers both in organic media [17] and in ILs [2,18,19]. This characteristic has been well described by Heinze et al. [18]. They associated the loop with an autocatalytic mechanism in which the oligomers formed during the first oxidation cycle react as redox mediators with the monomer, but this kind of loops is also characteristic of a nucleation and growth mechanism. The continuous increase of the current between -1.0 and $1.0 \mathrm{~V}$ with the number of cycles clearly indicates that the polymer film is growing. After ten cycles, the currents are higher for the film grown in $\operatorname{Pt}(111)$ than in $\operatorname{Pt}(110)$ or $\operatorname{Pt}(100)$ as it can be observed in Figure 1c. This behavior can be related to the fact that the $\operatorname{Pt}(111)$ is more catalytic for the electrodeposition of conducting polymers as it was observed in acetonitrile [6,9].

It is interesting to notice that during the first cycles the voltammograms show one oxidation peak and two negative peaks. In the case of $\operatorname{Pt}(111)$ and $\operatorname{Pt}(110)$ the oxidation peak appears at $0.37 \mathrm{~V}$ and the reduction peaks at $0.31 \mathrm{~V}$ and $-0.10 \mathrm{~V}$, which rapidly merge to one broad oxidation peak at $0.30 \mathrm{~V}$ and two reduction peaks at $-0.10 \mathrm{~V}$ and $-0.50 \mathrm{~V}$. However, in $\mathrm{Pt}(100)$ a peak grows at $0.50 \mathrm{~V}$ upon potential cycling, while another one

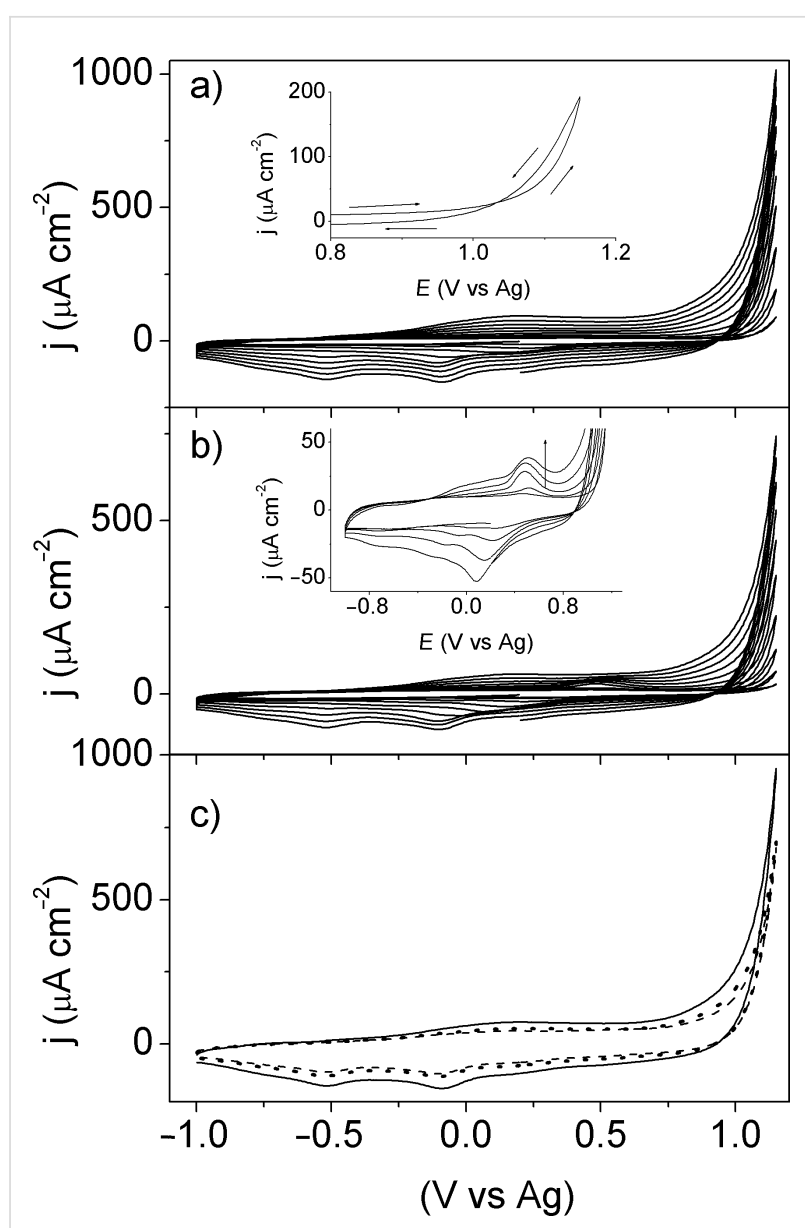

Figure 1: a, b) Cyclic voltammograms of $0.1 \mathrm{M}$ EDOT in [EMMIM] $\mathrm{Tf}_{2} \mathrm{~N}$ at $100 \mathrm{mV} \mathrm{s}^{-1}$. 10 cycles are shown: a) Pt(111), insert $-2^{\text {nd }}$ cycle; b) Pt(100), Insert - zoom of the cycles from 2 to $6, c) 10^{\text {th }}$ scan of figures "a" and "b" on Pt(111) (solid line), $\mathrm{Pt}(100)$ (dashed line) and $\operatorname{Pt}(110)$ (dotted line).

appears at $0.30 \mathrm{~V}$, as it can be observed in the Figure $1 \mathrm{~b}$ (insert graph). On the other hand, the two cathodic peaks at $0.30 \mathrm{~V}$ and $-0.03 \mathrm{~V}$ shift to lower potentials up to the values of $-0.10 \mathrm{~V}$ and $-0.50 \mathrm{~V}$, i.e., the same potentials observed for $\mathrm{Pt}(111)$ and $\operatorname{Pt}(110)$.

The peaks at $0.50 \mathrm{~V}$ and $0.30 \mathrm{~V}$ in $\mathrm{Pt}(100)$ can be produced by hydrogen oxidation and protons reduction, respectively, because these peaks appear at the same potentials where these reactions take place in [EMMIM] Tf $f_{2} \mathrm{~N}$ on $\operatorname{Pt}(100)$ [20]. Protons can be produced during the oxidation of EDOT and they can be reduced to hydrogen at negative potentials. These hydrogen reactions can inhibit the polymer growth on $\mathrm{Pt}(100)$ during the first cycles. Figure 1 clearly shows that the electrochemical polymerization of EDOT on platinum electrodes is a surface sensitive reaction. It was found that $\operatorname{Pt}(111)$ has the highest electrocatalytic activity for the EDOT oxidation reaction followed by $\operatorname{Pt}(110)$ and finally $\operatorname{Pt}(100)$. 
Taking into account that more reproducibility during the synthesis of conducting polymers is normally obtained using the galvanostatic method, the following experiments were done using PEDOT films galvanostatically synthesized.

Figure 2 shows the voltammograms of PEDOT in [EMMIM] $\mathrm{Tf}_{2} \mathrm{~N}$ free of monomer, in the potential range where the p-doping reaction is observed. Two broad oxidation and reduction signals are present after several cycles, as it was previously reported [19,21,22]. Domagala et al. [23] have provided strong experimental evidences that polarons represent the main charge carrier group in p-doped PEDOT. However, it is still unclear if the two oxidation signals in ionic liquids correspond to two different redox states (polarons and bipolarons) or if they are related to different polymer structures [4].

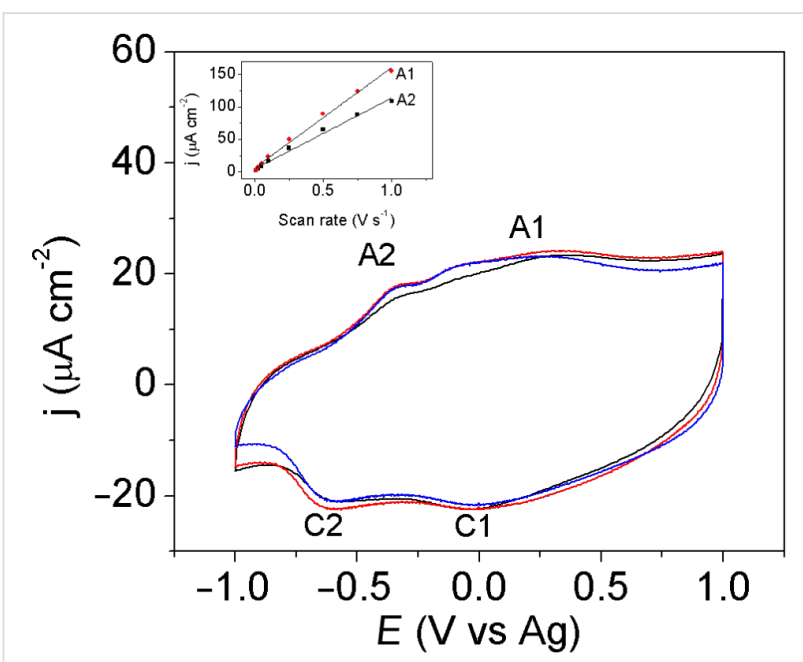

Figure 2: Cyclic voltammograms of PEDOT on Pt(111) (black line), $\mathrm{Pt}(100)$ (red line), $\mathrm{Pt}(110)$ (blue line) in [EMMIM]Tf ${ }_{2} \mathrm{~N}$ Scan rate $100 \mathrm{mV} \mathrm{s}^{-1}$. The films were synthesized applying a charge density of $1.2 \mathrm{mC} \mathrm{cm}{ }^{-2}$ during a chronopotentiometry. Insert graph: Current density vs scan rate of PEDOT on $\mathrm{Pt}(111)$.

Voltammetric profiles of PEDOT thin films in Figure 2 show that there are no significant differences between the Pt electrodes. On the other hand, the currents measured at 0.35 and $-0.30 \mathrm{~V}$ (A1 and A2) follow an almost linear tendency with the scan rate, which is characteristic of the surface controlled processes (Figure 2 - insert graph). As expected, thicker PEDOT films were obtained when the synthesis time was increased (Figure 3a).

Figure $3 \mathrm{~b}$ shows the voltammetry of a PEDOT film synthesized as in Figure 2, but transferred into a cell with $0.1 \mathrm{M}$ [EMMIM] $\mathrm{Tf}_{2} \mathrm{~N}$ in acetonitrile as supporting electrolyte. Many differences are observed between Figure $3 \mathrm{a}$ and Figure $3 \mathrm{~b}$ for the PEDOT films of the same thickness: the ratio between height of the cathodic peaks is different, the separation between
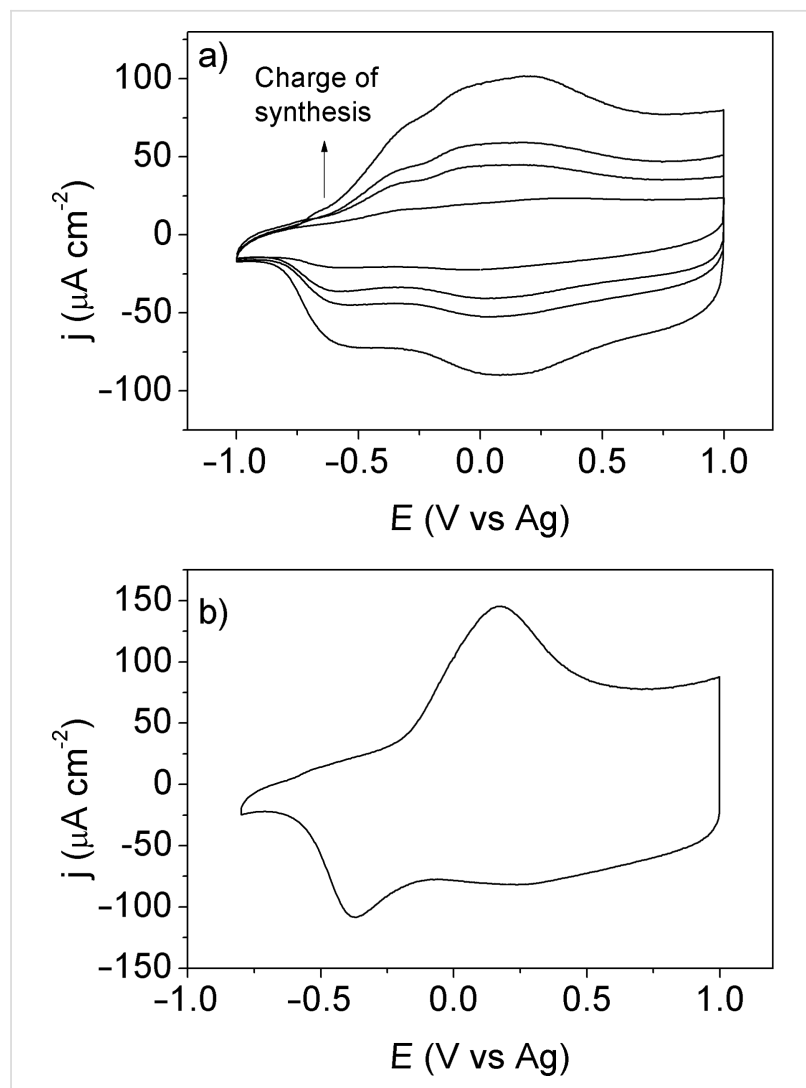

Figure 3: a) Cyclic voltammograms of PEDOT on $\mathrm{Pt}(111)$ in [EMMIM]Tf $f_{2} \mathrm{~N}$. The total charge densities used for the galvanostatic synthesis were $1.2,3.0,4.3$ and $6.2 \mathrm{mC} \mathrm{cm}^{-2}$, respectively. The scan rate was $100 \mathrm{mV} \mathrm{s}^{-1}$ and the $50^{\text {th }}$ scan is shown. b) Cyclic voltammogram of PEDOT on $\mathrm{Pt}(111)$ characterized in $0.1 \mathrm{M}$ [EMMIM]Tf ${ }_{2} \mathrm{~N}$ in acetonitrile. The total charge used during the PEDOT synthesis was $6.2 \mathrm{mC} \mathrm{cm}^{-2}$. The scan rate was $100 \mathrm{mV} \mathrm{s}^{-1}$.

the anodic and the cathodic peaks is smaller in pure [EMMIM] $\mathrm{Tf}_{2} \mathrm{~N}$ and the polymer is oxidized at lower potential in [EMMIM] $\mathrm{Tf}_{2} \mathrm{~N}$ than in acetonitrile.

\section{Chronoamperometry}

In order to maintain electroneutrality, the generation of charges in the conducting polymers must be accompanied with the entrance of counterions from the solution. The chronoamperometric experiments allow the study of the ionic exchange kinetics. Figures $4 \mathrm{a}-\mathrm{c}$ show the current traces when the potential is switched from $-1 \mathrm{~V}$ to $1 \mathrm{~V}$ and vice versa. It is observed that the transients of PEDOT films on the three Pt surfaces used are characteristic of nucleation kinetics [21].

The insert of Figure 4a shows the integrated charge, $Q_{\mathrm{i}}$, as a function of the charge of synthesis, $Q_{\mathrm{pol}}$. It can be observed that the charge involved in the current transient increases linearly with increasing polymerization charge. The reduction charge is slightly lower than the oxidation charge. It seems that during the oxidation step the film is slightly overoxidized. No signifi- 

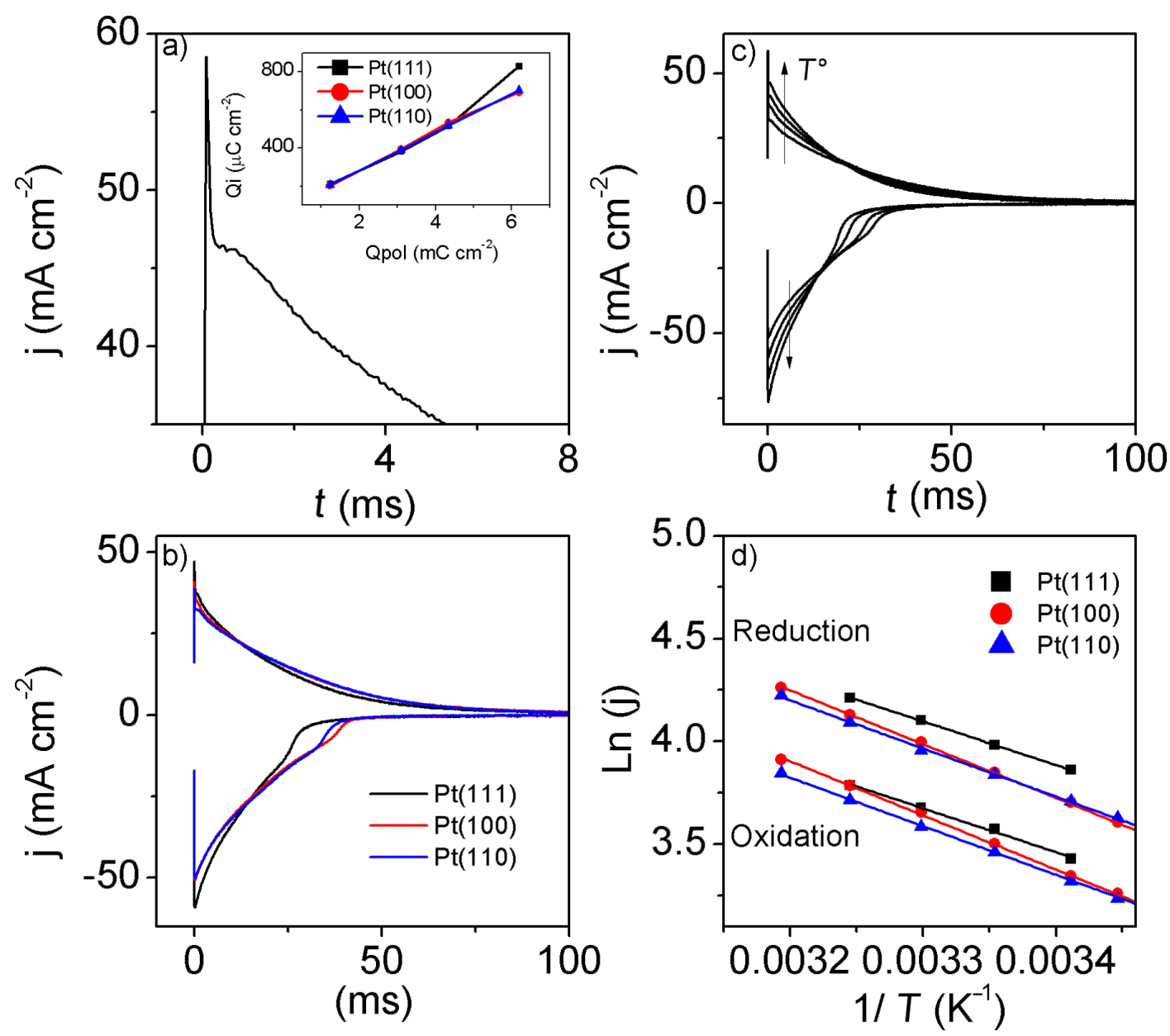

Figure 4: Chronoamperometry of PEDOT films synthesized on platinum single crystals in [EMMIM]Tf $f_{2} \mathrm{~N}$. The total synthesis charge was $6.2 \mathrm{mC} \mathrm{cm}-2$. The potential steps were between $-1.0 \mathrm{~V}$ and $1.0 \mathrm{~V}$. a) Zoom of the first milliseconds for the PEDOT film on Pt(111) at $35^{\circ} \mathrm{C}$. Insert: integrated charge of the chronoamperometry vs the synthesis electric charge for the Pt(hkl) electrodes. b) Chronoamperometry of PEDOT on Pt(hkl) at $25^{\circ} \mathrm{C}$. c) Chronoamperometry of PEDOT on Pt(111) at temperatures of $20,25,30$, and $35^{\circ} \mathrm{C}$. c) Logarithm of the current at $1.5 \mathrm{~ms}$ vs the inverse of temperature for: $\mathrm{Pt}(111)$ (black line), $\mathrm{Pt}(100)$ (red line) and $\mathrm{Pt}(110)$ (blue line).

cant differences were observed in the exchange kinetics for the different Pt surfaces (Figure 4b).

Figure $4 \mathrm{c}$ shows the current transients at different temperatures for the oxidation and reduction steps. The increase in temperature favors these processes as it has been observed for other conducting polymers $[24,25]$. With the value of the current at the very beginning of the transient $(1.5 \mathrm{~ms})$ it is possible to establish a relation between the current and the temperature using the "initial rate" approximation and the Arrhenius Equation. Since the logarithm of the current density vs the inverse of the temperature plot showed a linear dependence, Figure $4 \mathrm{~b}$, the apparent activation energy were calculated (Table 1).

The values of the activation energy for the oxidation and reduction processes are very similar and very close to the one reported for polythiophene $\left(16 \mathrm{~kJ} \mathrm{~mol}^{-1}\right)$ [24], which means that the oxidation and reduction of PEDOT (and the corresponding counterion exchange) occurs easily in spite of the fact that the viscosity of the ionic liquid is quite high [16]. It is important to state that the activation energy of the nucleation kinetics related to the ion exchange depends on the overpotential used. Even so, the results shown in Table 1, Figure 3a and Figure 4 show that the kinetics of the redox processes of PEDOT films is faster in [EMMIM] $\mathrm{Tf}_{2} \mathrm{~N}$ than in acetonitrile [6], which is a relevant characteristic feature for the use of PEDOT thin films to build electrochromic devices or actuators $[12,26,27]$.

\section{Morphology by AFM}

Figure 5 shows the AFM images of the polymer synthesized with a charge density of $1.2 \mathrm{mC} \mathrm{cm}^{-2}$ on the three Pt basal planes. It can be observed a grain shape with a low root mean square roughness (between $3 \mathrm{~nm}$ and $4 \mathrm{~nm}$ ). These results are in 
Table 1: Nucleation activation energies calculated from the linear graphs shown in Figure 4d.

\begin{tabular}{|c|c|c|c|c|c|c|c|}
\hline & & \multicolumn{2}{|c|}{ Intercept } & \multicolumn{2}{|c|}{ Slope } & \multicolumn{2}{|r|}{$\begin{array}{c}\text { Activation } \\
\text { energy }\end{array}$} \\
\hline \multicolumn{2}{|c|}{ Electrode } & Value & Standard error & Value & Standard error & $\mathrm{R}^{2}$ & $\mathrm{~kJ} \mathrm{~mol}^{-1}$ \\
\hline & Oxidation & 10.70 & 0.35 & -2130.27 & 106.15 & 0.993 & 17.71 \\
\hline \multirow[t]{2}{*}{$\operatorname{Pt}(111)$} & Reduction & 11.08 & 0.07 & -2116.69 & 22.11 & 1.000 & 17.60 \\
\hline & Oxidation & 12.34 & 0.12 & -2636.36 & 35.68 & 0.999 & 21.92 \\
\hline \multirow[t]{2}{*}{$\operatorname{Pt}(100)$} & Reduction & 12.64 & 0.10 & -2620.68 & 29.84 & 0.999 & 21.79 \\
\hline & Oxidation & 11.39 & 0.08 & -2364.92 & 22.83 & 0.999 & 19.66 \\
\hline $\operatorname{Pt}(110)$ & Reduction & 11.69 & 0.10 & -2341.47 & 28.85 & 0.999 & 19.47 \\
\hline
\end{tabular}

a) $\operatorname{Pt}(111)$

$10 \mu \mathrm{m} \times 10 \mu \mathrm{m}$

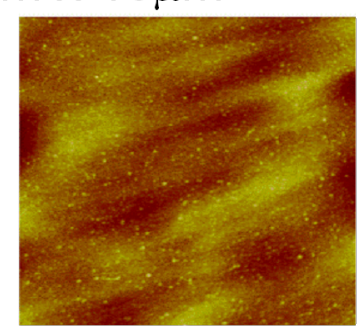

b) $\operatorname{Pt}(100)$
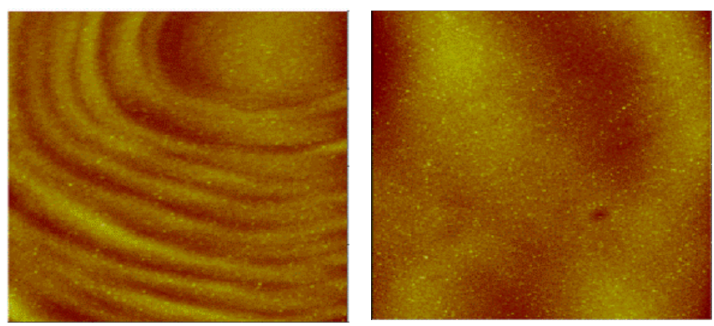

\section{$5 \mu \mathrm{m} \times 5 \mu \mathrm{m}$}
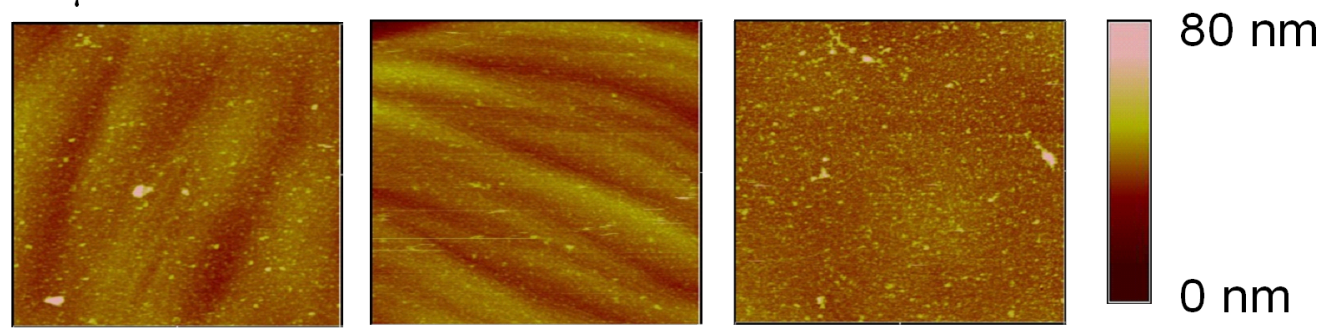

\section{$1 \mu \mathrm{m} \times 1 \mu \mathrm{m}$}
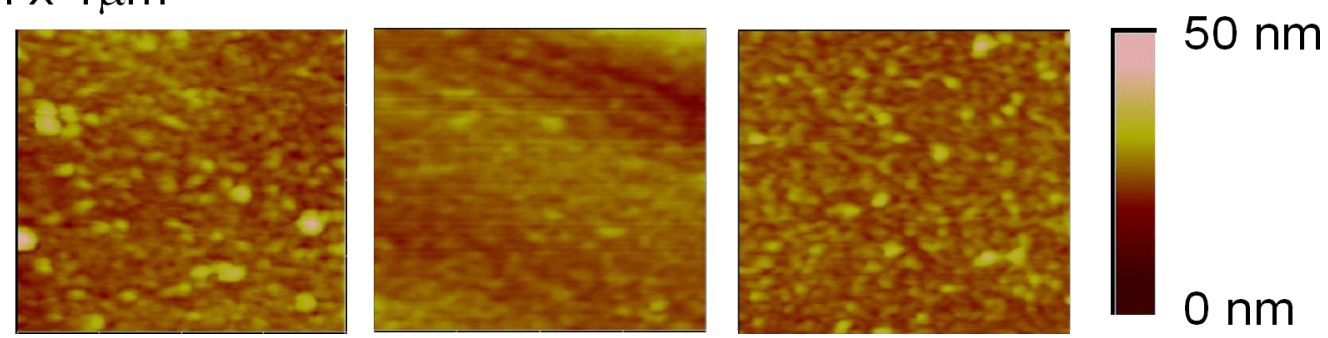

Figure 5: AFM images of PEDOT thin films synthesized on a) $\mathrm{Pt}(111), \mathrm{b}) \mathrm{Pt}(100)$ and c) $\mathrm{Pt}(110)$ with a charge density of $1.2 \mathrm{mC} \mathrm{cm}^{-2}$. The film thickness is approximately $10 \mathrm{~nm}$.

agreement with those obtained by MacFarlane et al. [13,28] which also reported very flat polymers in ILs. Opposite to the behavior obtained in aqueous or organic media, the synthesis in
ILs generates very flat and homogeneous polymers [29,30]. Specially in the case of $\operatorname{Pt}(100)$, the polymer follows the surface and its defects, indicating a two-dimensional growth [31]. 


\section{In situ FTIR}

When the vibrational behavior of PEDOT films is analyzed by in situ infrared spectroscopy, the observed bands depend on the applied potential. The reference potential in this case was $-0.9 \mathrm{~V}$ in order to start form the neutral form of PEDOT. Therefore, the positive bands correspond to products present in the oxidized form while the negative bands correspond to species consumption at the working potential.

Usually, PEDOT films are studied under attenuated total reflection conditions $[17,19,32]$ because it is difficult to distinguish between the bands coming from solution species and the bands coming from the polymer film. However, we found that it was possible to study the PEDOT behavior under external reflection conditions when very thin layers of polymer are used, as it can be observed in Figure 6 and Figure 7. A comparison between the solution spectrum of the IL and the $\mathrm{p}$ - and s-polarized spectra of the polymer is shown in Figure 6. The p-polarized spectrum shows a high absorption between 4000 and $2000 \mathrm{~cm}^{-1}$ typical of conducting polymers. This is an electronic absorption related to the formation of charge carriers [3]. However, this feature is not observed with the s-polarized light, which means that the p-polarized spectrum is effectively recording the behavior of the electrode surface. Also, it is important to recognize that there are no water bands, which means that the IL is practically dry.
The bands at 3186 and $3151 \mathrm{~cm}^{-1}$ in the p-polarized and ATR spectra, are related to the imidazolium cation. However, the intensity of these bands is very low, hindering their detection. The negative orientation of the bands in the p-spectra means that a considerable amount of cations is being exchanged during the oxidation of the polymer, as it has been reported previously $[5]$.

The zone between 1800 and $1000 \mathrm{~cm}^{-1}$ is complex because both polymer and IL bands are detected. The bands at 1334 , $1226 \mathrm{~cm}^{-1}$, related to the $\left[\mathrm{Tf}_{2} \mathrm{~N}\right]$ anion, are observed as negative bands both in the p-polarized and the s-polarized spectra which means that the anion is been consumed from the solution. Ispas et al. [33] reported that PEDOT film charge neutralization in ILs proceeds mostly by anion incorporation during the p-doping process, but for [EMIM] $\mathrm{Tf}_{2} \mathrm{~N}$ at $85{ }^{\circ} \mathrm{C}$ and [EMIM][OTf] at $25{ }^{\circ} \mathrm{C}$ the charge regulation occurs mainly via cation exchange. Our results show that, upon oxidation of the PEDOT films in [EMMIM] $\mathrm{Tf}_{2} \mathrm{~N}$ both cations and anions are switched but more cations than anions have to be exchanged in order to keep ion neutrality. In other words, it seems that during PEDOT redox cycling some part of the anions remain within the PEDOT film.

The bands related to the oxidation of the polymer and their assignment, based on the literature $[6,17,19,32,34]$, are listed in
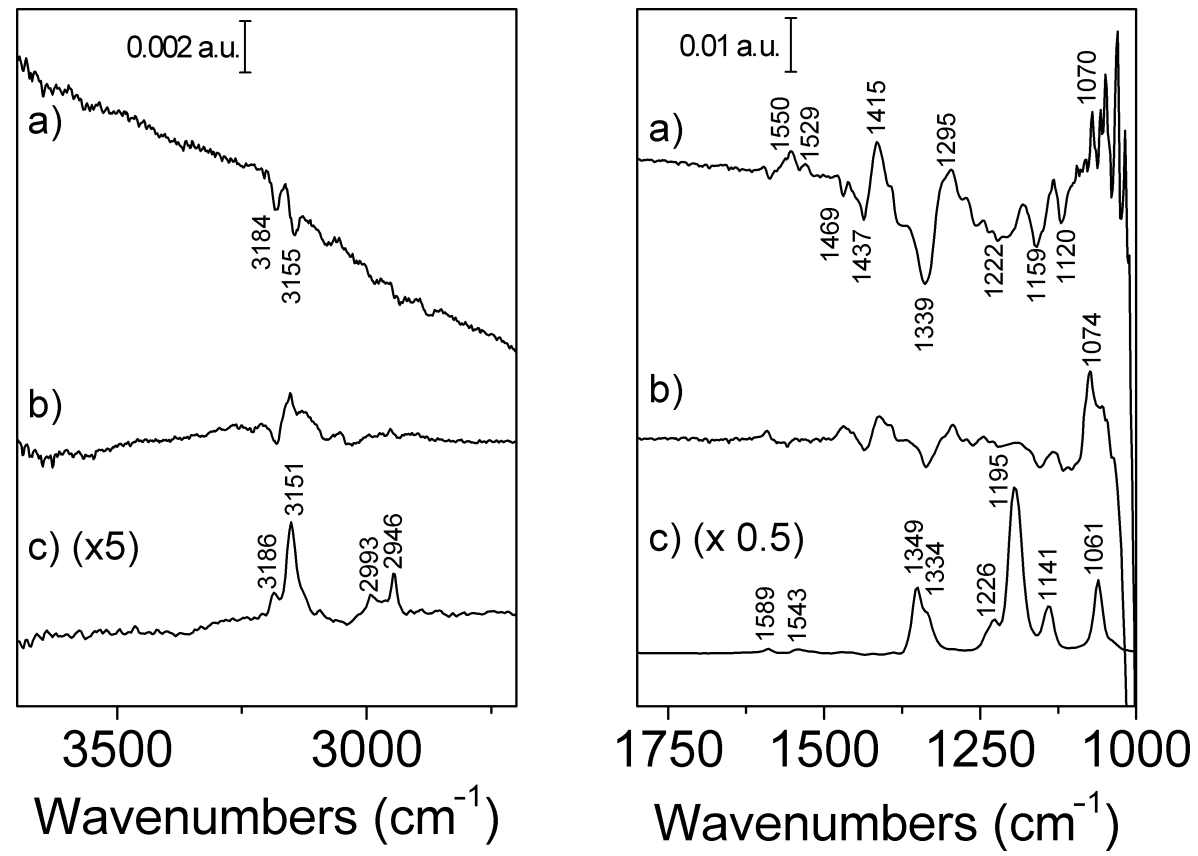

Figure 6: In situ FTIR spectra of a PEDOT thin film synthesized with a charge density of $0.6 \mathrm{mC} \mathrm{cm}^{-2}$ on Pt(111). 250 interferograms were recorded per spectrum. The reference potential was $-0.90 \mathrm{~V}$. a) p-Polarized spectrum at $0.80 \mathrm{~V}$. b) s-Polarized spectrum at $0.80 \mathrm{~V}$. c) ATR spectrum of $0.1 \mathrm{M}$ [EMMIM] $\mathrm{Tf}_{2} \mathrm{~N}$ in acetonitrile, obtained as the average of 100 interferograms. 

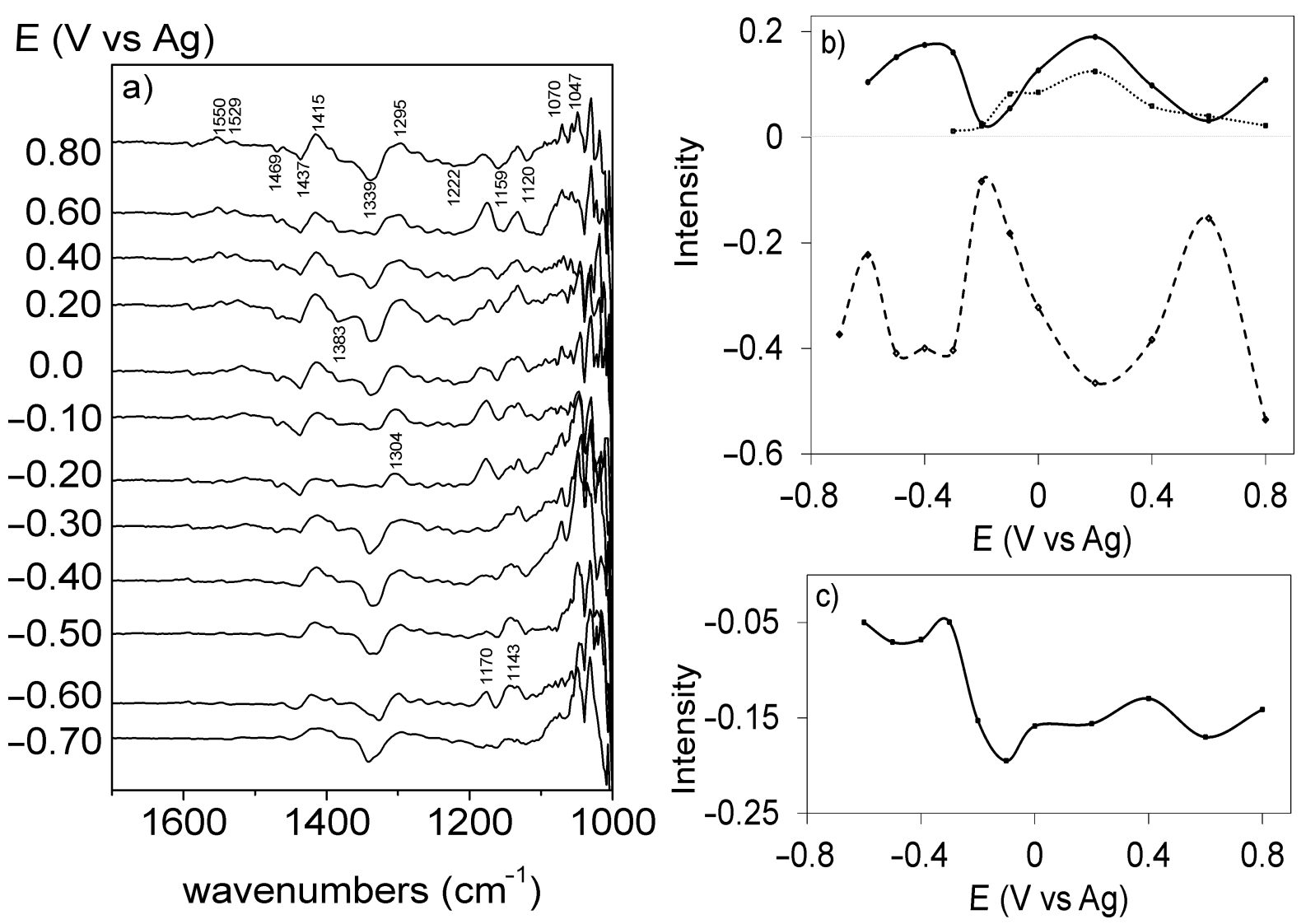

Figure 7: a) In situ FTIR spectra of a PEDOT thin film synthesized with a charge density of $0.6 \mathrm{mC} \mathrm{cm}^{-2}$ on Pt(111). 250 interferograms were recorded per spectrum. The reference potential was $-0.90 \mathrm{~V}$. Integrated IR intensities of several functional groups vs electrode potential:

b) $1415 \mathrm{~cm}^{-1}$ (solid line) doping induced band , $1529 \mathrm{~cm}^{-1}$ (dotted line) doping induced band; $1339 \mathrm{~cm}^{-1}$ (dashed line) $\mathrm{vas}_{2}\left(\mathrm{SO}_{2}\right.$ ); c) $1437 \mathrm{~cm}^{-1}$ (solid line) $v(C=C)$.

Table 2. The absorption bands at $1339 \mathrm{~cm}^{-1}$ and $1415 \mathrm{~cm}^{-1}$ can be assigned to the asymmetric stretching, $v_{\text {as }}$, of the $\mathrm{SO}_{2}$ moiety and the stretching of the thiophene ring in the oxidized state, respectively. Figure $7 \mathrm{~b}$ shows that there are two potential regions where significant changes of the IR peak intensity are observed, between $-0.6 \mathrm{~V}$ and $-0.2 \mathrm{~V}$ and between $-0.2 \mathrm{~V}$ and $0.6 \mathrm{~V}$. These are the same potential zones where the two reduction signals are observed (Figure $3 \mathrm{a}$ ). The two potential regions mean that there are two different processes, both related to p-doping, which can be related to two different redox or conformational states. It is important to notice that the intensity of these two signals oscillate out of phase in the potential range studied. Also, the band at $1132 \mathrm{~cm}^{-1}$ associated with the symmetric stretching of the $\mathrm{SO}_{2}$ is positive within the whole potential range showing an adsorption at the surface in which this vibrational mode is active. These features could mean that the consumption of anions (from the IL to inside the polymer) is directly related to the generation of positive charge, which occurs in two regions that correlate well with the peaks A1/C1 and $\mathrm{A} 2 / \mathrm{C} 2$ observed in Figure 2.
Also, the bands associated with the $\mathrm{C}=\mathrm{C}$ bonds in the thiophene ring (1437 and $1469 \mathrm{~cm}^{-1}$ ) are negative. The trend of the IR intensity at $1437 \mathrm{~cm}^{-1}$ (Figure 7c) shows a slight decrease from -0.7 to $-0.3 \mathrm{~V}$ and an abrupt fall at higher potentials. This trend closely resembles the currents observed during the p-doping of PEDOT (Figure 3a), suggesting that the disappearance of the $v(\mathrm{C}=\mathrm{C})$ stretching signal of the thiophene ring upon oxidation can be used to quantify the charge carriers inside the polymer. It seems that with increasing potential, the concentration of charge carriers (polarons) increases between $-0.3 \mathrm{~V}$ and $-0.1 \mathrm{~V}$ where a plateau is reached. This IR signal also behaves very similar as the EPR signal intensity upon changing potential reported by Domagala et al. [23].

Finally, it is important to remember that when a weak electric field is applied across a molecule, both the molecular vibrational energy levels and the transition dipoles between the levels change slightly. These changes affect the infrared absorption spectrum of the sample, i.e., the position and the intensity of the bands $[36,37]$. Taken into account that the IR spectra 
Table 2: Comparison between the absorption bands of ATR spectrum of $0.1 \mathrm{M}$ [EMMIM] $\mathrm{Tf}_{2} \mathrm{~N}$ in acetonitrile and external reflection FTIR spectra of PEDOT in [EMMIM]Tf ${ }_{2} \mathrm{~N}$.

\begin{tabular}{|c|c|c|}
\hline \multicolumn{2}{|c|}{ Wavenumber $\left(\mathrm{cm}^{-1}\right)$} & \multirow[t]{2}{*}{ Assignment } \\
\hline$\left.[\mathrm{EMIM}] \mathrm{Tf}_{2} \mathrm{~N}\right]$ & PEDOT & \\
\hline 3186 & $3186(n)$ & $\mathrm{v}(\mathrm{C}-\mathrm{H})$ ring $[34]$ \\
\hline 3151 & $3151(n)$ & $\mathrm{v}(\mathrm{C}-\mathrm{H})$ ring [34] \\
\hline 2993 & & $\mathrm{v}(\mathrm{C}-\mathrm{H})$ alkyl \\
\hline 2946 & & v(C-H) alkyl [34] \\
\hline 1589 & & $\mathrm{v}(\mathrm{C}=\mathrm{C})$ ring [35] \\
\hline \multirow[t]{6}{*}{1543} & & $\mathrm{v}(\mathrm{CH}-\mathrm{N})[35]$ \\
\hline & $1529(p)$ & Doping induced band [17] \\
\hline & $1469(n)$ & $\mathrm{v}(\mathrm{C}=\mathrm{C})[17,19]$ \\
\hline & $1437(n)$ & $v(C=C)[19]$ \\
\hline & $1415(p)$ & Doping induced band \\
\hline & $1381(n)$ & $\mathrm{v}(\mathrm{C}-\mathrm{C})[19]$ \\
\hline 1349 & & $\mathrm{v}_{\mathrm{as}}\left(\mathrm{SO}_{2}\right)[34]$ \\
\hline \multirow[t]{2}{*}{1334} & $1339(n)$ & $\mathrm{v}_{\mathrm{as}}\left(\mathrm{SO}_{2}\right)[34]$ \\
\hline & $1296(p)$ & $V_{\text {interring }}[17,19]$ \\
\hline 1226 & $1222(n)$ & $\mathrm{v}_{\mathrm{s}}\left(\mathrm{CF}_{3}\right)[34]$ \\
\hline \multirow[t]{2}{*}{1195} & & $\mathrm{v}_{\mathrm{as}}\left(\mathrm{CF}_{3}\right)[34]$ \\
\hline & $1176(p)$ & $\mathrm{v}(\mathrm{C}=\mathrm{C}), \mathrm{v}(\mathrm{COROC})[19]$ \\
\hline \multirow[t]{2}{*}{1141} & $1132(p)$ & $\mathrm{v}_{\mathrm{S}}\left(\mathrm{SO}_{2}\right)[34]$ \\
\hline & $1070(p)$ & v(COROC) $[17,19]$ \\
\hline \multirow[t]{2}{*}{1061} & & $\mathrm{v}_{\mathrm{as}}(\mathrm{SNS})[34]$ \\
\hline & $1045(p)$ & v(COROC) $[17,19]$ \\
\hline
\end{tabular}

(n) Negative oriented band; (p) positive oriented band; v: stretching; $\mathbf{s}$; symmetric; as: asymmetric; COROC: ethylenedioxy group.

were recorded at different potentials and that the ion orientation depends on the intensity and direction of the electric field at the interface, some influence of this effect on the spectra shown in Figure 7 is also expected. This effect can explain, in part at least, the complex behavior observed in Figure 7.

\section{Conclusion}

PEDOT films were synthesized on platinum single crystal electrode substrates in [EMMIM]Tf $f_{2} \mathrm{~N}$. Cyclic voltammetry shows that the polymer grows faster in $\operatorname{Pt}(111)$ than in $\operatorname{Pt}(110)$ or $\mathrm{Pt}(100)$. On the other hand, the chronoamperometric experiments show that the activation energy for the oxidation and reduction processes is very low and that the kinetics of the redox processes of PEDOT films is faster in [EMMIM]Tf ${ }_{2} \mathrm{~N}$ than in acetonitrile, which is very useful to build electrochromic devices or actuators.

$\operatorname{Pt}(111)$ and $\operatorname{Pt}(110)$ show almost the same characteristics in cyclic voltammetry, chronoamperometry and AFM experiments. On the other hand, polymer films grown on $\operatorname{Pt}(100)$ present marked differences, which suggests a different nucle- ation and growth mechanisms in this surface, probably a progressive 2D growth. Finally, the IR and voltammetric experiments show two potential zones where it seems that some changes on the structure and/or on the nature and number of charge carriers take place.

\section{Experimental}

The electrochemical experiments were performed in single compartment glass cells. A platinum wire was used as counter electrode, and a silver wire was used as the pseudoreference electrode. Platinum single crystals were used as working electrodes, which were prepared from small single-crystal beads following the Clavilier's method [38].

Prior to each experiment the cell was deareated with Ar ( $\geq 99.995 \%$ Alphagaz). The electrodes were heated in a gas-oxygen flame, cooled down in a reductive atmosphere $\left(\mathrm{H}_{2}+\mathrm{Ar}\right)$ and protected with a droplet of the IL at temperatures low enough to avoid decomposition. Then, the electrode was positioned in contact with the IL using a meniscus configuration.

1-Ethyl-2,3-dimethylimidazolium triflimide ([EMMIM] $\mathrm{Tf}_{2} \mathrm{~N}$ ), $>99 \%$ purity, was purchased from Iolitec. It was purified prior to use as it has been previously reported [20].

Polymer films were grown under galvanostatic conditions (unless otherwise stated) by applying a current density of $0.124 \mathrm{~mA} \mathrm{~cm}^{-2}$ during $5,10,25,35$ or $50 \mathrm{~s}$ in a solution of 0.1 M 3,4-ethylenedioxythiophene (EDOT, Sigma-Aldrich 97\%). After the electropolymerization, the PEDOT films were rinsed with ionic liquid free of monomer and then positioned in contact with fresh ionic liquid using a meniscus configuration. 50 scans were performed to ensure a stable voltammetric profile. Characterization was also made in a solution of $0.1 \mathrm{M}$ [EMMIM] $\mathrm{Tf}_{2} \mathrm{~N}$ in acetonitrile (Sigma-Aldrich, anhydrous, $99.8 \%)$

A commercially available potentiostat/galvanostat $\mu$ Autolab III (Ecochemie) was used for the electrochemical experiments. The morphology of the polymer was studied with a NanoScope III Multimed contact AFM. Scan rate of $2 \mathrm{~Hz}$. A standard cantilever of $\mathrm{Si}_{3} \mathrm{~N}_{4}$ with piramidal tips (Digital Instruments) were used.

In situ Fourier Transform Infrared spectroscopy (FTIR) experiments were performed with a Nexus 8700 (Thermo Scientific) spectrometer equipped with an MCT detector. The spectroelectrochemical cell was provided with a prismatic $\mathrm{CaF}_{2}$ window beveled at $60^{\circ}$. Spectra shown are composed of 250 interferograms and were collected with a resolution of $4 \mathrm{~cm}^{-1}$. Unless 
otherwise stated, the spectra were collected with p-polarized light. They are presented as absorbance, according to $A=-\log \left(R / R_{0}\right)$, where $R$ and $R_{0}$ are the reflectance corresponding to the single-beam spectra obtained at the sample and reference potentials, respectively [39]. The contact of the electrodes with the IL was performed at a potential where the polymer was reduced $(-0.90 \mathrm{~V})$. This potential was maintained while the electrode was pressed against the $\mathrm{CaF}_{2}$ window. After collecting the reference spectrum at this potential, the potential was stepped progressively to higher potentials up to $0.80 \mathrm{~V}$ waiting 5 minutes between steps to ensure the stability within the thin layer.

Attenuated total reflection configuration (ATR) was used to obtain the spectra of $0.1 \mathrm{M}$ [EMMIM]Tf $\mathrm{f}_{2} \mathrm{~N}$ in acetonitrile using a $\mathrm{ZnSe}$ hemicylindrical window with an incident angle of $45^{\circ}$. The reference spectrum was obtained in acetonitrile. The spectra are composed by 100 interferograms with a resolution of $8 \mathrm{~cm}^{-1}$.

\section{Acknowledgements}

APS acknowledges the scholarship "Estudiantes sobresalientes de posgrado" at the "Universidad Nacional de Colombia (UNAL)" and COLCIENCIAS National Doctoral Scholarship (567). MFS acknowledges support of UNAL (Research Project 19030). JMF thanks MINECO (Spain) support through project CTQ2013-44083-P and Generalitat Valenciana (Feder) through project PROMETEOII/2014/013.

\section{References}

1. Inzelt, G. J. Solid State Electrochem. 2011, 15, 1711-1718. doi:10.1007/s10008-011-1338-3

2. Heinze, J.; Frontana-Uribe, B. A.; Ludwigs, S. Chem. Rev. 2010, 110, 4724-4771. doi:10.1021/cr900226k

3. Elschner, A.; Kirchmeyer, S.; Lövenich, W.; Merker, U.; Reuter, K. PEDOT: principles and applications of an intrinsically conductive polymer; CRC Press: Boca Raton, 2011.

4. Inzelt, G. Conducting Polymers. A New Era in Electrochemistry; Springer Verlag: Berlin, Heidelberg, 2008. doi:10.1007/978-3-540-75930-0

5. Randriamahazaka, H.; Bonnotte, T.; Noël, V.; Martin, P.; Ghilane, J.; Asaka, K.; Lacroix, J.-C. J. Phys. Chem. B 2011, 115, 205-216. doi:10.1021/jp1094432

6. Suárez-Herrera, M. F.; Costa-Figueiredo, M.; Feliu, J. M. Phys. Chem. Chem. Phys. 2012, 14, 14391-14399. doi:10.1039/c2cp42719b

7. Lang, P.; Clavilier, J. Synth. Met. 1991, 45, 297-308. doi:10.1016/0379-6779(91)91786-A

8. Hidalgo-Acosta, J. C.; Climent, V.; Suárez-Herrera, M. F.; Feliu, J. M. Electrochem. Commun. 2011, 13, 1304-1308. doi:10.1016/j.elecom.2011.07.021

9. Suárez-Herrera, M. F.; Feliu, J. M. Phys. Chem. Chem. Phys. 2008, 10, 7022-7030. doi:10.1039/b812323c
10. Suárez-Herrera, M. F.; Feliu, J. M. J. Phys. Chem. B 2009, 113, 1899-1905. doi:10.1021/jp8089837

11. Jeon, S. S.; Park, J. K.; Yoon, C. S.; Im, S. S. Langmuir 2009, 25, 11420-11424. doi:10.1021/la901563n

12. Lu, W.; Fadeev, A. G.; Qi, B.; Smela, E.; Mattes, B. R.; Ding, J.; Spinks, G. M.; Mazurkiewicz, J.; Zhou, D.; Wallace, G. G.; MacFarlane, D. R.; Forsyth, S. A.; Forsyth, M. Science 2002, 297, 983-987. doi:10.1126/science.1072651

13. MacFarlane, D. R.; Pringle, J. M.; Howlett, P. C.; Forsyth, M. Phys. Chem. Chem. Phys. 2010, 12, 1659-1669. doi:10.1039/b923053j

14. Pringle, J. M.; Efthimiadis, J.; Howlett, P. C.; Efthimiadis, J.; MacFarlane, D. R.; Chaplin, A. B.; Hall, S. B.; Officer, D. L.; Wallace, G. G.; Forsyth, M. Polymer 2004, 45, 1447-1453. doi:10.1016/j.polymer.2004.01.006

15. Fuchigami, T.; Inagi, S. Electrolytic Reactions. In Electrochemical Aspects of lonic Liquids, 2nd ed.; Ohno, H., Ed.; John Wiley \& Sons, Inc.: New Jersey, 2011; pp 101-127. doi:10.1002/9781118003350.ch8

16. Galiński, M.; Lewandowski, A.; Stępniak, I. Electrochim. Acta 2006, 51, 5567-5580. doi:10.1016/j.electacta.2006.03.016

17. Kvarnström, C.; Neugebauer, H.; Blomquist, S.; Ahonen, H. J.; Kankare, J.; Ivaska, A. Electrochim. Acta 1999, 44, 2739-2750. doi:10.1016/S0013-4686(98)00405-8

18. Heinze, J.; Rasche, A.; Pagels, M.; Geschke, B. J. Phys. Chem. B 2007, 111, 989-997. doi:10.1021/jp066413p

19. Damlin, P.; Kvarnström, C.; Ivaska, A. J. Electroanal. Chem. 2004, 570, 113-122. doi:10.1016/j.jelechem.2004.03.023

20. Sandoval, A. P.; Suárez-Herrera, M. F.; Feliu, J. M. Electrochem. Commun. 2014, 46, 84-86. doi:10.1016/j.elecom.2014.06.016

21. Sandoval, A. P.; Feliu, J. M.; Torresi, R. M.; Suárez-Herrera, M. F. RSC Adv. 2014, 4, 3383-3391. doi:10.1039/c3ra46028b

22. Randriamahazaka, H.; Plesse, C.; Teyssié, D.; Chevrot, C. Electrochem. Commun. 2003, 5, 613-617. doi:10.1016/S1388-2481(03)00142-5

23. Domagala, W.; Pilawa, B.; Lapkowski, M. Electrochim. Acta 2008, 53, 4580-4590. doi:10.1016/j.electacta.2007.12.068

24. Otero, T. F.; Santos, F. Electrochim. Acta 2008, 53, 3166-3174. doi:10.1016/j.electacta.2007.10.072

25. Otero, T. F.; Grande, H.-J.; Rodriguez, J. J. Phys. Chem. B 1997, 101 , 3688-3697. doi:10.1021/jp9630277

26. Pozo-Gonzalo, C.; Mecerreyes, D.; Pomposo, J. A.; Salsamendi, M.; Marcilla, R.; Grande, H.; Vergaz, R.; Barrios, D.; Sánchez-Pena, J. M. Sol. Energy Mater. Sol. Cells 2008, 92, 101-106. doi:10.1016/j.solmat.2007.03.031

27. Lu, B.; Zhang, S.; Qin, L.; Chen, S.; Zhen, S.; Xu, J. Electrochim. Acta 2013, 106, 201-208. doi:10.1016/j.electacta.2013.05.068

28. Pringle, J. M.; Forsyth, M.; MacFarlane, D. R.; Wagner, K.; Hall, S. B.; Officer, D. L. Polymer 2005, 46, 2047-2058. doi:10.1016/j.polymer.2005.01.034

29. Sekiguchi, K.; Atobe, M.; Fuchigami, T. J. Electroanal. Chem. 2003, 557, 1-7. doi:10.1016/S0022-0728(03)00344-9

30. Suárez, M. F.; Compton, R. G. J. Electroanal. Chem. 1999, 462, 211-221. doi:10.1016/S0022-0728(98)00414-8

31. Milchev, A. Electrocrystalization, Fundamentals of Nucleation And Growth; Kluwer Academic Publishers: New York, 2002.

32. Kvarnström, C.; Neugebeauer, H.; Ivaska, A.; Sariciftci, S. J. Mol. Struct. 2000, 521, 271-277. doi:10.1016/S0022-2860(99)00442-1 
33. Ispas, A.; Peipmann, R.; Bund, A.; Efimov, I. Electrochim. Acta 2009, 54, 4668-4675. doi:10.1016/j.electacta.2009.03.056

34. Motobayashi, K.; Minami, K.; Nishi, N.; Sakka, T.; Osawa, M. J. Phys. Chem. Lett. 2013, 4, 3110-3114. doi:10.1021/jz401645c

35. Moschovi, A. M.; Ntais, S.; Dracopoulos, V.; Nikolakis, V.

Vib. Spectrosc. 2012, 63, 350-359. doi:10.1016/j.vibspec.2012.08.006

36. Boxer, S. G. J. Phys. Chem. B 2009, 113, 2972-2983. doi:10.1021/jp8067393

37. Hermansson, K. J. Chem. Phys. 1993, 99, 861-868. doi:10.1063/1.465349

38. Korzeniewski, C.; Climent, V.; Feliu, J. M. Electrochemistry at Platinum Single Crystal Electrodes. In Electroanalytical Chemistry: A Series of Advances; Bard, A. J.; Zoski, C. G., Eds.; CRC Press: Boca Raton, 2012; pp 75-166.

39. Osawa, M. In-situ Surface-Enhanced Infrared Spectroscopy of the Electrode/Solution Interface. In Advances in Electrochemical Science and Engineering: Diffraction and Spectroscopic Methods in Electrochemistry; Alkire, R. C.; Kolb, D. M.; Lipkowski, J.; Ross, P. N., Eds.; Wiley-VCH Verlag GmbH: Weinheim, 2006. doi:10.1002/9783527616817.ch8

\section{License and Terms}

This is an Open Access article under the terms of the Creative Commons Attribution License

(http://creativecommons.org/licenses/by/2.0), which permits unrestricted use, distribution, and reproduction in any medium, provided the original work is properly cited.

The license is subject to the Beilstein Journal of Organic Chemistry terms and conditions:

(http://www.beilstein-journals.org/bjoc)

The definitive version of this article is the electronic one which can be found at: doi:10.3762/bjoc. 11.40 